\title{
O USO DE TECNOLOGIAS NA INCLUSÃO DIGITAL, ESCOLAR E SOCIAL DE ESTUDANTES PÚBLICO- ALVO DA EDUCAÇÃO ESPECIAL COM PARALISIA CEREBRAL
}

Fernanda Oliveira Sabino ${ }^{1}$, Ana Mayra Samuel Silva ${ }^{2}$, Ana Virginia Isiano Lima ${ }^{2}$, Elisa Tomoe Moriya Schlünzen ${ }^{3}$

${ }^{1}$ Graduada em Tecnologia Informática pela Faculdade de Tecnologia, campus de Mococa/SP. ${ }^{2}$ Graduanda em Pedagogia na Universidade Estadual Paulista - UNESP -Presidente Prudente - SP. ${ }^{3}$ Docente da Universidade Estadual Paulista - UNESP - Presidente Prudente - SP. E-mail: fernanda.2010@hotmail.com

\section{RESUMO}

As atividades dos integrantes do grupo de pesquisa Ambientes Potencializadores para Inclusão, API, visam oferecer recursos para o desenvolvimento social e cognitivo dos estudantes Público Alvo na Educação Especial atendidos nele. O objetivo é preparar os alunos para facilitar o dia-adia na escola e contribuir para seu relacionamento interpessoal. Cada aluno realiza atividades relacionadas com os conhecimentos prévios que eles trazem da sua vivencia e o aluno estagiário responsável utiliza os recursos de acessibilidade pertinentes ao seu tipo de necessidade. Neste projeto estão sendo utilizadas tecnologias como o computador, objetos de aprendizagem adequada às necessidades físicas e ferramentas como por exemplo a colméia. Como resultado espera-se que as pessoas com Paralisia Cerebral, PPC desenvolvam sua coordenação motora e sensorial e realizem atividade possibilitando a aprendizagem e realizando tarefas anteriormente impossíveis.

Palavras-Chave: Palavras chave: Paralisia Cerebral, Relacionamento Interpessoal, Estudantes Público-Alvo da Educação Especial.

\section{INTRODUÇÃO E OBJETIVO}

O principal objetivo da equipe do grupo de pesquisa API, é buscar meios que proporcionem a inclusão digital, social e escolar de Estudantes Público Alvo da Educação Especial, (EPAEE), que recebem acompanhamentos individualizados semanais. As atividades são escolhidas de acordo com o interesse e necessidade de cada um, visando desenvolver o potencial e habilidades, bem como a preparação para assumir papéis sociais que diminuam a discriminação advindas de suas limitações e dificuldades.

Neste ambiente são atendidos alunos Portadores de Paralisia Cerebral (PPC), que utilizam o computador e ferramentas para que eles possam desenvolver a coordenação motora e sensorial. A pesquisa se encontra em andamento e neste estágio pretende-se mostrar a metodologia adequada para colaborar com a aprendizagem do PPC. A adequação das ferramentas e recursos didáticos no processo ensino-aprendizagem é muito importante neste processo de atendimento. 


\section{CONSIDERAÇÕES TEÓRICAS}

A Paralisia Cerebral é uma deficiência de foro neurológico que afeta as funções básicas do ser humano (fala, postura e movimento). O nome técnico desta deficiência é Dismotria Cerebral Ontogenética (DCO), ocasionada por uma falta de oxigenação numa parte do cérebro (encéfalo), quando este ainda esta em formação. As causas mais comuns são infecções ou traumatismos que ocorrem antes, durante ou após o nascimento. (MARTINS, 2008). Os tipos de paralisia cerebral são classificados de acordo com suas alterações motoras e sensoriais causadas pelas lesões que podem ser extensas ou não no cérebro. Dependendo da área atingida, é que se da a classificação como: tipo espástica, atetóse, cerebelar e ataxia.(LIMONGI,1998).

Segundo a visão Vygotskyana as pessoas não se desenvolvem para se submeter a um processo de ensino de aprendizagem sistematizado ou formalizado, nem se desenvolvem e aprendem ao mesmo tempo. Dessa forma o individuo faz que ocorra uma mudança no lugar social onde vive, pois todos nós nascemos com uma única capacidade, a de aprender. Isto implica que o local onde o PPC realizada atividades de aprendizagem e tão importante quanto as atividades realizadas.

\section{METODOLOGIA}

O acompanhamento no grupo de pesquisa API, das alunas R., Y., ambas PPC, iniciou-se no ano 2012. Em Março de 2013, reiniciou-se o acompanhamento, já foram alfabetizadas e apesar de suas limitações, utilizam recursos de acessibilidade como computador (teclado, mouse), acessam redes sociais, e-mail, e realizam a leitura de gibis e livros infantis. Estão desenvolvendo sua coordenação motora e a fala da sua maneira e tempo.

A partir das informações adquiridas por meio de um diálogo com as alunas e responsáveis, elaboramos planos de ensino para favorecer a aprendizagem no ano de 2013, baseados no trabalho com projetos e realizando atividades de uso das TDIC (Tecnologias Digitais de Informação e Comunicação).

Pelas características apontadas e dialogadas com cada PPC serão utilizadas diferentes ferramentas: com a das alunas K, o uso da adaptação de hardware, chamado de Colmeia, que consiste numa placa de plástico ou acrílico com perfurações correspondentes a cada tecla do teclado, que quando fixada a uma certa distância acima deste, tem por finalidade evitar que a pessoa que apresenta movimentos involuntários pressione teclas indesejadas. Com a aluna Y., utilizaremos softwares educacionais como jogos de estratégias simulação e execução, 
apresentação de conteúdo. Com a aluna R., serão utilizados aplicativos editores de texto, internet para uso de pesquisa livre e orientada e ferramentas da web e mídias. A mesma atualmente criou um blog para publicar seus trabalhos artesanato e suas leituras de interesse, pois tem um sonho de ser escritora de contos românticos.

\section{RESULTADOS}

Neste momento da pesquisa podemos dizer que as ferramentas utilizadas são adequadas para as limitações apresentadas pelas PPC. O fato de alcançar a alfabetização no ano 2012 utilizando as ferramentas descritas na metodologia se apresenta como um resultado parcial positivo o que indica que os recursos de acessibilidade para amenizar as barreiras causadas por esta deficiência são adequados para o processo de aprendizagem.

Se faz necessário um estudo aprofundado dos softwares, as ferramentas que o computador oferece e o estudo de trabalhos com PPC. Segundo Santarosa (2002), aprender com o computador não é possuir informações, senão saber acessar e processar a informação; é interativo, envolve uma comunicação com a máquina, que favorece a tomada de consciência, pelo educando, no planejamento de suas ações, no processo de reflexão sobre suas ações e no controle sobre sua aprendizagem. Isto favorece e motiva a relação do PPC com o mundo.

\section{DISCUSSÕES}

A pesquisa refere se a pessoas com paralisia cerebral com diferentes idades e com suas limitações (cognitivas e físicas), nos acompanhamentos do CPIDES, com o intuito de facilitar o processo de aprendizagem e o desenvolvimento interpessoal, nem todos os alunos frequentam escola.

\section{CONCLUSÃO}

Segundo Almeida \& Fonseca (2000):

O que traz a felicidade ao ser humano? É ser livre para fazer o bem e faze-lo bem feito. Ao fazer bem minhas ações torno-me bom com as coisas que construo. Se fizer coisas boas, elas também me tornarão bom. Eu as construo e elas me constroem. Desse modo, o bem e o belo andam juntos, inseparáveis.

Contudo pode-se afirmar que a educação especial e tecnologia podem caminhar juntos e com o mesmo objetivo: Inclusão. Essa ferramenta desde que bem utilizada poderá trazer 
evoluções consideráveis. Diminuindo a exclusão e mostrar ao mundo que não são apenas padrões físicos que devem ser levados em conta, mas sim éticos, morais e intelectuais.

\section{REFERÊNCIAS}

ALMEIDA, M. E. Projeto: uma nova cultura de aprendizagem. São Paulo: PUC/SP, 1999.

LIMONGI, Suelly Cecilia Olivan. Paralisia cerebral: linguagem e cognição. 2.ed. rev., ampliada, atual. São Paulo: Pró- Fono, 1998.

MARTINS, Lúcia de Araújo Ramos (org). Escola Inclusiva: pesquisa, reflexões e desafios. João Pessoa: Idéia, 2008.

VYGOSTSKY, L.S. Formação Social da Mente. 6o Edição. São Paulo.Martins Fontes, 1997.

SANTAROSA, L.M. C Ambientes Digitais de Aprendizagem e Inclusão - mediação pelas áreas de desenvolvimento potencial de pessoas com necessidades educativas especiais, 2002. 